\title{
AVALIAÇÃo CLÍNICA DO BÓCIO ENDÊMICO
}

Yaro Ribeiro Gandra*

GANDRA, Y. R. Avaliação do bócio endêmico. Rev. Saúde públ., S. Paulo, 18: 396-404, 1984.

RESUMO: É feita uma revisão das principais classificaçōes clínicas do bócio endêmico,colocando-se em destaque as divergências normativas existentes entre elas. Enfatiza-se a importância do diagnóstico clínico da hipertrofia incipiente da glândula tiróide no acompanhamento da evolução da endemia bociosa através da vigilância epidemiológica. Sugere-se uma adaptação metodológica no exame clínico do bócio endêmico.

UNITERMOS: Bócio endêmico, diagnóstico. Glândula tiróide.

O bócio endêmico representa, ainda hoje, uma das endemias alimentares específicas mais difundidas, constituindo em alguns paises sério problema de saúde pública, não so. mente pela extensão com que atinge certos grupos populacionais como, também, pelas sérias consequêencias que dele advêm.

A III Reunião Especial de Ministros de Saúde das Américas, realizada em Santiago do Chile, em $1972^{13}$, estabeleceu as metas de ação para a década, com o objetivo de reduzir a prevalência do bócio endêmico a menos de $10 \%$ e eliminar o cretinismo endêmico'no hemisfério.

Embora muitos países americanos já tenham introduzido a iodataçَ̃o do sal de con. sumo, aquelas metas ainda não foram total. mente atingidas.

O comitê científico assessor da Organização Panamericana de Saúde, já em 1961, ao considerar os problemas de saúde dos paises da América Latina, emprestava alta prioridade ao bócio endêmico. Este comitê, direta ou indiretamente, estimulou os cientistas desses países a investigarem a prevalência do bócio endêmico, assim como a apresentarem seus resultados aos respectivos governos para que medidas concretas de controle fossem colocadas em prática. Hoje em dia, a maioria dos países das Américas conta com programa de iodatação do sal, técnica esta de grande eficácia em si, mas que, por questões políti. co-administrativas, nem sempre tem conseguido reduzir o bócio endêmico a taxas aceitáveis.

O objetivo do presente trabalho é o de tecer comentários sobre as diferentes técnicas clínicas de levantamento do bócio endêmico.

Várias classificaçōes e técnicas de diagnóstico clínico do bócio endêmico têm sido utilizadas. Entretanto, apesar de semelhantes, não são totalmente correspondentes, principalmente quando se referem às hipertrofias iniciais, isto $e$, aquelas que definem o momento inicial do crescimento anormal da glândula, e, portanto, classificando-a como bócio ou não.

Não é fácil saber até que ponto pode se considerar uma glândula tiróide normal.

$O$ peso e $O$ tamanho da glândula tiróide dependem evidentemente da idade fisioló. gica, do sexo, da raça, dos hábitos, do lugar de origem e de permanência do indivíduo, de seu padrão genético, além de outras caracte. rísticas. Levando esses itens em consideração pode-se dizer que, no adulto, cada lóbulo da tiróide tem de 4 a $6 \mathrm{~cm}$ de altura, $2,5 \mathrm{~cm}$ de largura e pouco mais de $1,5 \mathrm{~cm}$ em sua maior espessura. $O$ ístmo, geralmente com $2,0 \mathrm{~cm}$ de comprimento, raramente passa de $0,5 \mathrm{~cm}$ de altura e $0,2 \mathrm{~cm}$ de espessura. $O$ peso médio da tiróide normal varia, no adulto, de 20 a $25 \mathrm{~g}$ podendo, segundo alguns, chegar a 30 ou $35 \mathrm{~g}$. A maioria dos autores considera

* Do Departamento de Nutrição da Faculdade de Saúde Pública da Universidade de São Paulo - Av. Dr. Arnaldo, 715 - 01255 - São Paulo, SP - Brasil. 
que, geralmente, a tiróide normal não tem mais que $0,35 \mathrm{~g}$ por quilograma de peso do indivíduo adulto. A glândula acima de $35 \mathrm{~g}$ já é considerada definitivamente como bó. cio. Nas crianças o peso da glândula varia entre 2 e $11 \mathrm{~g}$, este último, na pré-puberdade (14 anos); já nos adolescentes o peso da glândula atinge cerca de $18 \mathrm{~g}$.

MacLennan e Gaitan ${ }^{4}$, examinando escola. res em Rozo no Vale de Cauca, na Colombia e utilizando a classificação da Organização Mundial da Saúde, encontraram, para tiróides normais, áreas que variaram de 4,2 a 4,9 $\mathrm{cm}^{2}$; para o bócio de grau I de 6,0 a $8,2 \mathrm{~cm}^{2}$ e para o de grau II, de 11,5 a $14,2 \mathrm{~cm}^{2}$. O diagnóstico do bócio endêmico pode ser feito por meio de exames clínicos, bio. químicos e anatomopatológicos. Entre os exa. mes bioquímicos, é a excreção urinária diá ria de iodo que nos poderá dar, mais facilmente, subsídios para a interpretação da endemia bociosa.

Quando a excreção urinária de iodo estiver entre 25 e 50 microgramas por grama de creatinina, geralmente a formação hormonal já deve estar prejudicada e já há risco de hi. potiroidismo, porém pouco risco de cretinis. mo endêmico. Nestas condições o bócio predominante é de grau OB ou 1. Quando a con. centração média de iodo for menor que 25 microgramas por grama de creatinina já há risco de cretinismo endêmico ${ }^{12}$.

Dada as dificuldades de se acompanhar um programa de controle do bócio endêmico através de provas químicas, é o exame clínico aquele de preferência em saúde pública.

O levantamento clínico do bócio endêmico poderá abranger toda a comunidade. Este proceder nos vai oferecer uma visão bastante satisfatória do progresso da endemia bociosa na área. $\mathrm{O}$ encontro de grandes bócios, difusos ou nodulares, em adultos, concomitantes com a baixa prevalência dessa patolo. gia em crianças, sugere que houve endemia grave no passado e que, na ocasião, a causa determinante do bócio está reduzida. $O$ inverso, isto é, a baixa prevalência de bócio em adulto e alta prevalência em crianças nos su. gerirá que um fato novo está induzindo o aparecimento do bócio nessa comunidade.
O grupo populacional escolhido para o exame clínico está pois na dependência do objetivo que se quer atingir.

Quando se quer fazer simplesmente o acompanhamento pela vigilância epidemioló. gica do bócio endêmico em área sujeita ou não a um programa de intervenção, ou mes. mo quando se quer comparar áreas distintas, nem sempre há necessidade de se estudar to. da a população. Tendo em vista ser comum a carência de recursos humanos e da infra-es. trutura dos serviços, opinamos que se deva escolher um grupo determinado da população, que então servirá como termômetro sensível às variações das prevalências do bócio na área. Para isso basta eleger o grupo mais sensível à endemia bociosa e de mais fácil acesso pelos serviços habituais de atendimento à população. Esse grupo é o que chamamos de Grupo Vulnerável Indicador (GVI) que, para o caso do bócio, seria constituído por escolares de ambos os sexos e de 9 a 14 anos de idade. São estes que, pela fase fisiológica que atravessam, relacionada ao crescimento e aos fenômenos pré-puberais, os que mais prontamente adquirem o bócio. Elegendo assim o GVI do bócio endêmico, padroniza-se a avaliação da prevalência na área e melhor se a compara com as de áreas distintas. A análise deste grupo poderá trazer sugestões para um estudo mais aprofundado das hipertrofias da tiróide no resto da população.

São os escolares, na realidade, o grupo operacional de mais fácil acesso podendo ca. da examinador proceder ao exame clínico em cerca de 100 escolares por hora de trabalho efetivo.

Vários critérios para a classificação de bócio endêmico foram propostos no decorrer dos anos. Alguns autores, como Pales ${ }^{7}$, na África, consideram bócio toda tiróide "palpável". Enquanto que outros classificam como bócio toda tiróide que, à inspecção, mostrar-se visivel.

No levantamento feito pelo Departamen. to Nacional de Saúde em 1955 (Pellon e $\mathrm{col}^{8}{ }^{8}$ ), considerou-se bócio endêmico as glândulas visíveis à inspecção. Medeiros Filho ${ }^{6}$, apresentando o inquérito nacional da SU. CAM (1974-76), aceita como tiróide normal 
quando os "lobos laterais têm o volume igual ao das falanges distais dos polegares" e coloca no grau $\mathrm{OB}$ aquelas glândulas "aumentadas de volume" em relação a essa mesma normal. Alguns autores ${ }^{5}$ traçando o perfil da superfície da tiróide, compararam o tamanho da glândula à palpação, com modelos de plasticina que eles mesmos criaram após exames detalhados.

Acreditamos ser de todo interesse associar a palpação à inspecção uma vez que é muito importante que na palpação se estime o tamanho da glândula e sinta-se, ao mesmo tempo, a consistência e a regularidade da superfície da tiróide.

A hipertrofia tiroidiana pode apresentar formas nodulares mesmo em glândulas com peso dentro da normalidade e até em glându. las atrofiadas. São os nódulos manifestaçōes secundárias e representam a expressão do tempo em que o indivíduo ficou exposto à deficiência. São mais freqüentes nas mulheres e sua prevalência varia de região para região. Toda vez que um bócio se reduz co. mo conseqüência, por exemplo, da suplementação de iodo, os eventuais nódulos pré. existentes tornam-se mais identificáveis à pal. pação. Os nódulos respondem mal à iodação.

Geralmente a glândula com nódulos palpáveis pesa mais que $35 \mathrm{~g}$ e esses nódulos têm mais que $10 \mathrm{~mm}$ de diâmetro.

Várias são as classificações apresentadas no decorrer do tempo (Tabela), todas com pequenas adaptaçðes próprias o que poderá trazer dificuldades na comparação de resultados, principalmente na análise da evolução da endemia durante a vigilância epidemio. lógica do bócio endêmico.

Uma das classificações mais citadas é a de Perez e col.$^{10}$ que admitem como bócio, aque. las tiróides que, à palpação, representam um tamanho de 4 a 5 vezes maior que o normal e que são visíveis à inspecção com a cabeça em posição estendida. $\mathrm{O}$ aumento da glându. la inferior àquele tamanho não é classificado como bócio pelos autores.

Quase que unanimemente considera-se ti. róide normal aquela que, à palpação, representa tamanho correspondente à unha do po. legar do indivíduo examinado. Esta seria a glândula normal, enquanto que bócio, para muitos ${ }^{10}, 14$, seria aquela glândula cujo tama. nho à palpação representasse ser maior que a falange distal do polegar do indivíduo examinado.

Ora, desde logo percebe-se que há entre o "normal" (tamanho da unha do polegar) e o bócio incipiente (tamanho da falange distal do polegar) uma hipertrofia tiroidiana que fica entre esses dois valores e que não é levada em consideração.

A primeira reunião da "PAHO Scientific Group on Endemic Goiter", Caracas, $1963^{9}$, apresentou modificações na classificação de Perez e col. ${ }^{10}$, dividindo 0 grupo normal 0 (zero) em $0 A$ e $O B$ tornando assim a classificação mais sensivel para a fase inicial de aumento tiroidiano.

As pequenas, mas importantes, divergências entre as diferentes classificaçőes propostas ou as modificações sobre a classificação original de Perez e col. ${ }^{10}$ podem ser analisadas na Tabela.

De Smet ${ }^{3}$ citando Perez e col. ${ }^{10}$ não se refere ao tamanho da tiróide normal como fizeram aqueles autores; neste mesmo artigo ele define para o grau 1 as "tiróides palpa. bles que solo se hace visible con los movimientos de degluticion", não se referindo também ao tamanho da glândula.

De $\mathrm{Smet}^{3}$ considera as tiróides grau 2 aquelas visíveis quando o pescoço está estendido, portanto, em franco desacordo com as demais classificações que consideram a tiróide assim percebida como de grau 1. Também classifica a glândula no grau 3 quando, pelas características que aponta, os demais autores colocam-na no grau 2, isto é, "bócio visible sin extension del cuello". Em um grau 4 coloca os bócios volumosos.

Pretell e col. ${ }^{11}$, citando a reunião de Caracas, apresenta classificação que subdivide o bócio grau 0 (zero), em OA e OB colocando, neste último, os bócios já detectáveis pela palpação, não se referindo igualmente ao ta. manho que assim poderia ser percebido.

Stanbury e col. ${ }^{14}$ apresentam uma adaptação da mesma classificação de Perez e col. ${ }^{10}$, mas coloca no grau $0 \mathrm{~A}$ as "Thyroid not palpable, or, if palpable not larger than 
normal" e no grau OB, as tiróides "distinctly palpable but usually not visible" com a cabeça em qualquer posição, embora coloquem aqui as tiróides com tamanho, no mínimo, tão grandes quanto a falange distal do polegar do indivíduo. Estes autores também não mencionaram aquelas tiróides hipertrofiadas que, embora maiores que as normais, não atingiram ainda $o$ tamanho do polegar do examinado.

No grau 1 esses autores ${ }^{14}$ colocam as tiróides "easely palpable" e visíveis com a cabeça em "normal or raised position" diferen. ciando este grau do grau 2 porque neste últi. mo elas são "easely visible" com a cabeça em posição normal. Ora, nem sempre é fácil saber o que é visível em posição normal e o que é facilmente visível em posição normal. MacLennan e Gaitan ${ }^{4}$, adotando o sistema da WHO com modificações baseadas no que foi proposto pelo primeiro grupo científico da PAHO em Caracas, $1963^{9}$, não subdividem o grau zero e classificam como grau 1 as tirói. des visíveis com o pescoço em extensão ou com a deglutição e que, à palpação, são iguais ou maiores que duas vezes o tamanho da glândula normal. Incluem, portanto, um novo parâmetro dimensional para se classifi. car a tiróide como bócio.

A comissão de especialistas ${ }^{12}$ reunida pa. ra definir bócio endêmico e cretinismo,assim como para oferecer uma classificação dos seus diferentes graus, apresentou pequenas modificações ao sistema de Perez e col. ${ }^{10} \mathrm{li}$ mitando-se à observação de ser a tiróide visível ou não e palpável ou não, sem entretanto definir tamanhos comparativos.

Clements $^{1}$ citando Perez e col. ${ }^{10}$ também não subdivide 0 grau zero e não classifica $o$ bócio segundo parâmetros dimensionais.

DeMayer e col. ${ }^{2}$ fazendo uma revisão atualizada do trabalho de Perez e col. ${ }^{10}$, apresentam uma classificação que procura sintetizar as demais fontes autorizadas. Nesta classificação o bócio la (correspondente ao $0 \mathrm{~B}$ ) não deverá ser visível a inspecção, en. tretanto, dependendo da delgadeza do pescoço do examinado, a glândula poderá ser visivel quando a cabeça estiver estendida. Este bócio, segundo esses autores, é "manifes. tadamente palpável" enquanto que no grau 1 b ele o é "facilmente palpável". Ao nosso ver, falta um limite de grandeza para distínguir, pela palpação, estes dois graus de bócio.

Classificações de outros autores poderiam ser trazidas aqui, porém estas, de pesquisado. res de renome na área de bócio endêmico, já mostram a falta de homogeneidade nos crité. rios para a classificação do bócio endêmico.

As diferenças resultantes no uso de uma ou de outra classificação são de interesse não só para o diagnóstico, mas, e principalmente, para a vigilância epidemiológica.

$O$ estabelecimento de conceitos bem definidos e uniformes é de importância, principalmente no diagnóstico dos graus iniciais do bócio, uma vez que são estes graus aque. les que classificam o indivíduo como possui. dor ou não de bócio, e portanto definem o resultado final da prevalência.

Este aspecto toma relevo por ocasião da organização de um sistema de vigilância do bócio endêmico quando então as hipertrofias iniciais crescem de importância tanto na cons. tatação da redução eventual do bócio instala. do como no aparecimento de casos novos dentro de classes homogêneas da comunidade.

Foi pois na iminência de se organizar um sistema de vigilância epidemiológica para $o$ bócio endêmico no Brasil, que resolvemos reexaminar essas classificações e sugerir uma outra modalidade que, com maior clareza, se defina os diferentes graus de bócio de maneira a facilitar a interpretação da evolução da prevalência dessa endemia ( $T a b e l a)$. A maior preocupação residiu na classificação da glân. dula que já é maior que a normal (tamanho da unha do polegar), mas que não atingiu ainda 4 a 5 vezes o tamanho desta (normal). Este aumento inicial da glândula tiróide, independetemente de sua etiologia, poderá oferecer uma informação útil quando se quer analisar medidas de controle do bócio, principalmente em áreas de baixa ou moderada endemicidade. Os bócios iniciais, menos fibrosos, são os de mais fácil regressão. $O$ bócio grau $\mathrm{OB}$ seria, à palpação, maior que $\mathrm{O}$ tamanho normal (tamanho da unha do polegar), porém menor que 4 a 5 vezes este tamanho. $\mathrm{O}$ bócio 1 seria aquele em que, à ins. 
T A B E L A

Classificações clínicas alternativas de bócio, propostas por vários autores.

\begin{tabular}{|c|c|c|c|c|c|}
\hline $\begin{array}{l}\text { Bócio } \\
\text { Grau }\end{array}$ & Perez e col..$^{10}$ & $\begin{array}{l}\text { DeSmet } \\
\text { Perez }^{30}\end{array}$ & DeSmet $^{3}$ & Pretell e col. ${ }^{11}$ & Stanbury e col. ${ }^{14}$ \\
\hline $\mathbf{O A}$ & $\begin{array}{l}\mathrm{I} \cdot \\
\mathrm{P} \cdot<4 \cdot 5 \times \mathrm{N}\end{array}$ & $\begin{array}{l}\text { I - } \\
\text { P - Não palpável } \\
\text { ou }<4 \text { - } 5 \times \mathrm{N}\end{array}$ & $\begin{array}{l}\text { I - } \\
\text { P- Não palpável }\end{array}$ & I - Sem Bócio & $\begin{array}{l}\text { I - } \\
\text { P - Não palpável } \\
\text { ou } \leqslant \text { Normal }\end{array}$ \\
\hline $\mathrm{OB}$ & & & & $\begin{array}{l}\text { I - Não visível } \\
\text { P - Palpável }\end{array}$ & $\begin{array}{l}\text { I - Geral/ não visí- } \\
\text { vel } \\
\text { P - } \geqslant \text { polegar }\end{array}$ \\
\hline 1 & $\begin{array}{l}\text { I - Visível CE } \\
P-\geqslant 4-5 \times N\end{array}$ & $\begin{array}{l}\text { I - Visível CE } \\
\text { P - Palpável }\end{array}$ & $\begin{array}{l}\text { I - Vis. somente } \\
\text { c/ deglutição } \\
\text { P - Palpável }\end{array}$ & $\begin{array}{l}\text { I - Visível CE } \\
\text { P - }\end{array}$ & $\begin{array}{l}\text { I - Visível CN ou } \\
\text { CE } \\
\text { P - Facil/palpável } \\
\text { ou nódulo }\end{array}$ \\
\hline 2 & $\begin{array}{l}\text { I - Visível CN } \\
\text { P - }\end{array}$ & $\begin{array}{l}\text { I - Visível CN } \\
\text { P - }\end{array}$ & $\begin{array}{l}\text { I - Visível CE } \\
\text { P - }\end{array}$ & $\begin{array}{l}\text { I - Visível CN } \\
\text { P - }\end{array}$ & $\begin{array}{l}\text { I - Vis. facil/ CN } \\
\text { P - }\end{array}$ \\
\hline 3 & $\begin{array}{l}\text { I - Visível grde. } \\
\text { distância }\end{array}$ & I - Volumoso & $\begin{array}{l}\text { I - Visível CN } \\
\text { P - }\end{array}$ & $\begin{array}{l}\text { I - Visível grde } \\
\text { distância } \\
\text { P - }\end{array}$ & $\begin{array}{l}\text { I - Visível a dis- } \\
\text { tância } \\
\text { P. }\end{array}$ \\
\hline 4 & & & I - Volumoso & $\begin{array}{c}\text { I - Visível grde } \\
\text { distância } \\
\text { Monstruoso }\end{array}$ & $\begin{array}{l}\text { I - Monstruoso } \\
\text { I - }\end{array}$ \\
\hline $\begin{array}{r}\mathrm{N} \\
\mathrm{Vis} \\
\mathrm{CN} \\
\mathrm{CE}\end{array}$ & $\begin{array}{l}=\text { Normal } \\
=\text { Visível } \\
=\text { Cabeça posição } \\
=\text { Pescoço plenan }\end{array}$ & mal & & & continua.. \\
\hline
\end{tabular}


continuação

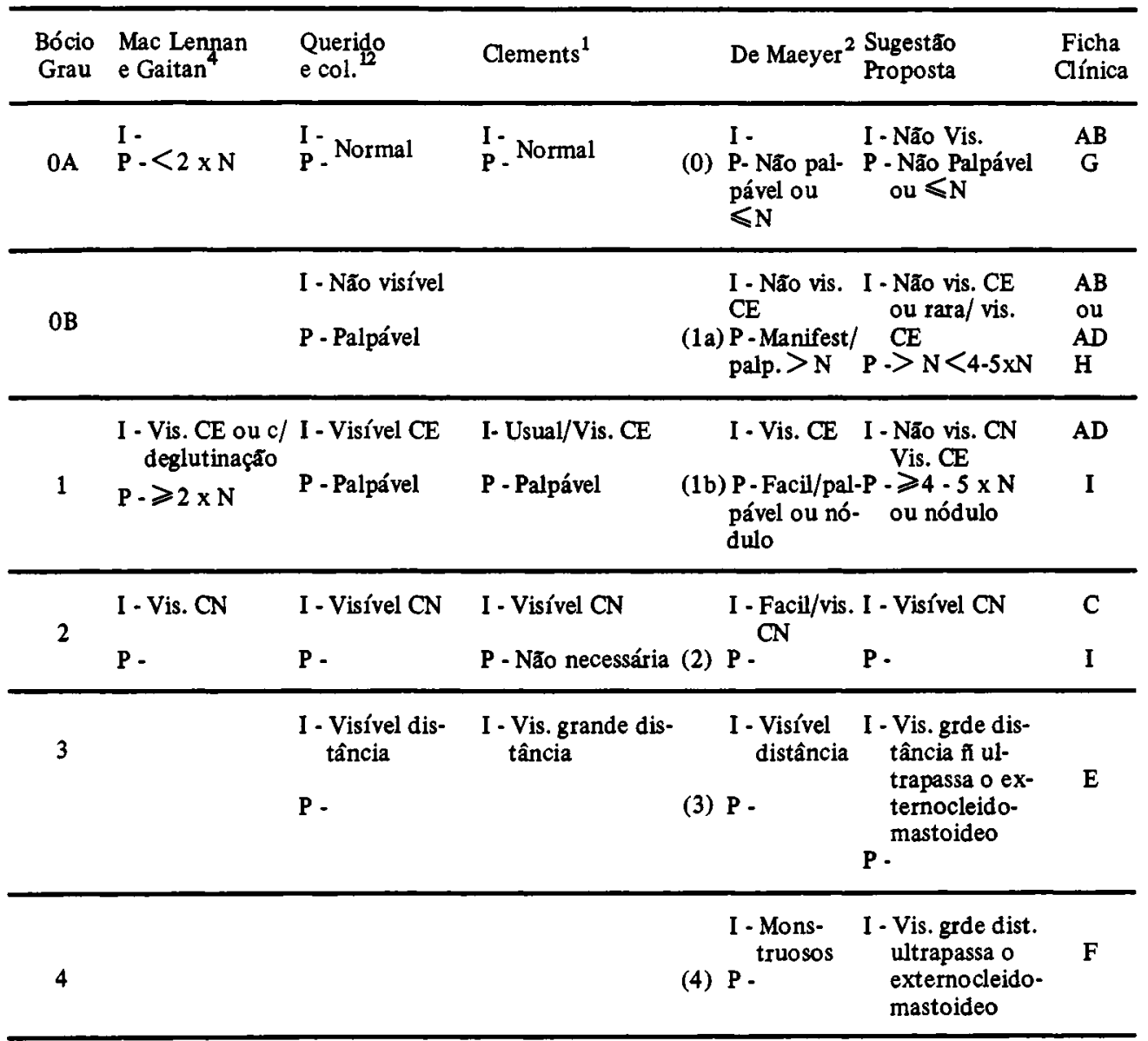

$\mathrm{N}=$ Norma

Vis $=$ Visível

$\mathrm{CN}=$ Cabeça posição normal

$\mathrm{CE}=$ Pescoৎ̧o plenamente estendido 
peç̧ão, não seria visível com a cabeça em posição normal porém visível com o pescoço estendido e, à palpação, se apresentaria igual ou maior que 4 a 5 vezes o tamanho normal.

Por outro lado, na eventualidade de se avaliar a evolução da endemia bociosa, tendo como população índice, não somente o GVI do bócio, mas toda a comunidade, seria útil distinguir-se nos graus 3 e 4 a diferença entre "bócio visível a distância" (a que distância?) e "bócios mostruosos".

Acreditamos que se se escolher, como limite, os bordos externos do externocleido. mastoideo, poderíamos, com mais segurança, perceber a eventual redução do bócio adulto, ainda que, sendo geralmente fibrosos e nodulares, mudem pouco o seu volume, quando, por exemplo, sob programa de suplementa. ção iódica.

Para minimizar os enganos de uma classificação apressada, conforme sói acontecer em trabalhos de campo, sugerimos que na ficha trazida pelo examinado,conste apenas os resultados da inspecção e da palpação, deixando para etapa imediata a classificação em graus conforme sugerido no Modelo de ficha (Anexo).

Para finalizar gostaríamos de relembrar alguns pontos a serem considerados na vigilância de uma endemia bociosa. Deve-se levar em consideração que existe, com freqüência, redução espontânea de casos de bócio, bem observável em área de baixa endemicidade; em área de maior endemicidade esta redução espontânea é desprezível. 0 número de examinados varia. Para uma área de $20 \%$ de bócio, por exemplo, ómínimo de examinados seria de 200 a 300 quando então se poderia esperar um erro de $20 \%$ com os processos usualmente seguidos.

Considera-se área de bócio endêmico quando mais de $5 \%$ de seus pré e peri-adolescentes portam bócio grau 1 ou, $30 \%$ de grau OB ou mais (Stanbury e col. ${ }^{14}$ ) na po. pulação. É considerada também região en. dêmica aquela em que mais de $10 \%$ dos individuos, adultos ou não, portam nódulos tiroidianos. $O$ cretinismo endêmico só é geralmente encontrado em área onde mais de $20 \%$ da população tem grau 1 ou mais.

Queremos, mais uma vez, chamar a atenção para a importância de se adotar metodo. logias e classificações uniformes na identificação e na graduação do bócio, com o propósito de permitir a comparação de resultados de áreas distintas ou de acompanhar, em vigilância, a evolução da endemia quando sujeita a programas de controle do bócio en. dêmico.

GANDRA, Y. R. [Clinic evaluation of endemic goiter]. Rev. Saúde públ., S. Paulo, 18:396404, 1984.

ABSTRACT: A review of the principal clinical classifications of endemic goiter was carried out and the existing normative divergences emphasized. The importance of the clinical diagnosis of incipient hypertrophy of the thyroid gland on the epidemiologic surveillance of endemic goiter was considered. A methodologic adaptation for the clinical diagnosis of endemic goiter was suggested.

UNITERMS : Goiter, endemic, diagnosis. Thyroid gland.

\section{REFERENCIAS BILIOGRÄFICAS}

1. CLEMENTS, F. W. Endemic goiter. In: World Health Orgzanization. Nutrition in preventive medicine. Geneva, 1976. p. 83-93.

2. DeMAEYER, E. M. La lucha contra el bocio endemico. Ginebra, Organizacion Mundial de la Salud, 1979.
3. DeSMET, M. P. Anatomia patologica del bocio endemico. In: Organizacion Mundial de la Salud. El bocio endemico. Ginebra, 1965. p. 341-77. (OMS-Série de Monografias 44).

4. MacLENNAN, R. \& GAITAN, E. Measurement of thyroid size in epidemiologic sur- 
vey. In: Meeting of the PAHO Technical Group on Endemic Goiter, 49, Guarujá, SP, 1973. Endemic goiter and cretinism. continuing threats to world health report. Washington, D. C., Pan American Health Organization, 1974. p. 195-7. (PAHO-Scient. publ., 292).

5. MacLENNAN, R. GAITAN, E. \& MILLER, M. C. Observer variation in grading and measuring the thyroid in epidemiological surveys. In: Meeting of the PAHO Scientific Group on Research in Endemic Goiter, Puebla, Mexico, 1968. Report. Washington, D. C., Pan American Health Organization, 1969. p. 67-77.

6. MEDEIROS FLLHO, A. Magnitude atual do problema do bócio endêmico no Brasil. Brasilia, INAN, 1978. [Apresentado ao Seminário sobre Bócio Endêmico no Brasil, Brasília, 1978].

7. PALES, M. L. Le goitre endémique en A. O. $F$. d'après l'enquête du service de Santé en 1948: faits et hypotheses. Presse méd., 58 (35):622, 1950 .

8. PELLON, A. B. et al. Areas bocigenas do Brasil. Rio de Janeiro, Departamento Nacional de Saúde, 1956.

9. PAN AMERICAN HEALTH ORGANIZATION. Report of Scientific Group on Research in Endemic Goiter. Caracas, 1963.

10. PEREZ, C.; SCRIMSHAW, N. S. \& MUÑOZ, J. A. Tecnica de las encuestas sobre el bocio endemico. In: Organizacion Mundial de la Salud. El bocio endemico. Ginebra, 1967. p. 399-414. (OMS-Série de Monografias, 44).

11. PRETELL, E. A.; MONCLOA, F.; SALINAS, R.; KAWANO, A.;GUERRA-GARCIA, R.; GUTIERREZ, L.; BETETA, L.; PRETEL, J. \& WAN, M. Prophylaxis and treatment of endemic goiter in Peru with iodized oil. $J$. clin. Endoc. Metab., 29:1586-95, 1969.

12. QUERIDO, A.; DELANGE, F.; DUNN, J. T.; FIERRO-BENITEZ, R.; IBBERTSON, $\mathrm{H}$. K.; KOUTRAS, D. A. \& PERINETTI, $H$. Definitions of endemic goiter and cretinism, classification of goiter size and severity of endemias, and survey techniques. In: Meeting of the PAHO Technical Group on Endemic Goiter, 4ㅇ, Guarujá, SP, 1973. Endemic goiter and cretinism: continuing threats to world health; report. Washington, D. C., Pan American Health Organization, 1974. p. 267-72 (PAHO - Scient. Publ., 292).

13. REUNION Especial de Ministros de Salud de las Americas, 3a, Santiago, Chile, 1972. Washington, D. C., Organización Panamericana de la Salud, 1973.

14. STANBURY, J. B.; ERMANS, A. M.; HETZEL, B. S.; PRETELL, E. A. \& QUERIDO, A. Endemic goiter and cretinism: public health significance and prevention. WHO chron., $28: 220-8,1974$.

Recebido para publicação em 21/05/1984. Aprovado para publicaçāo em 17/08/1984. 
Modelo de Ficha clínica de avaliação de Bócio Endêmico

$$
\text { (frente) }
$$

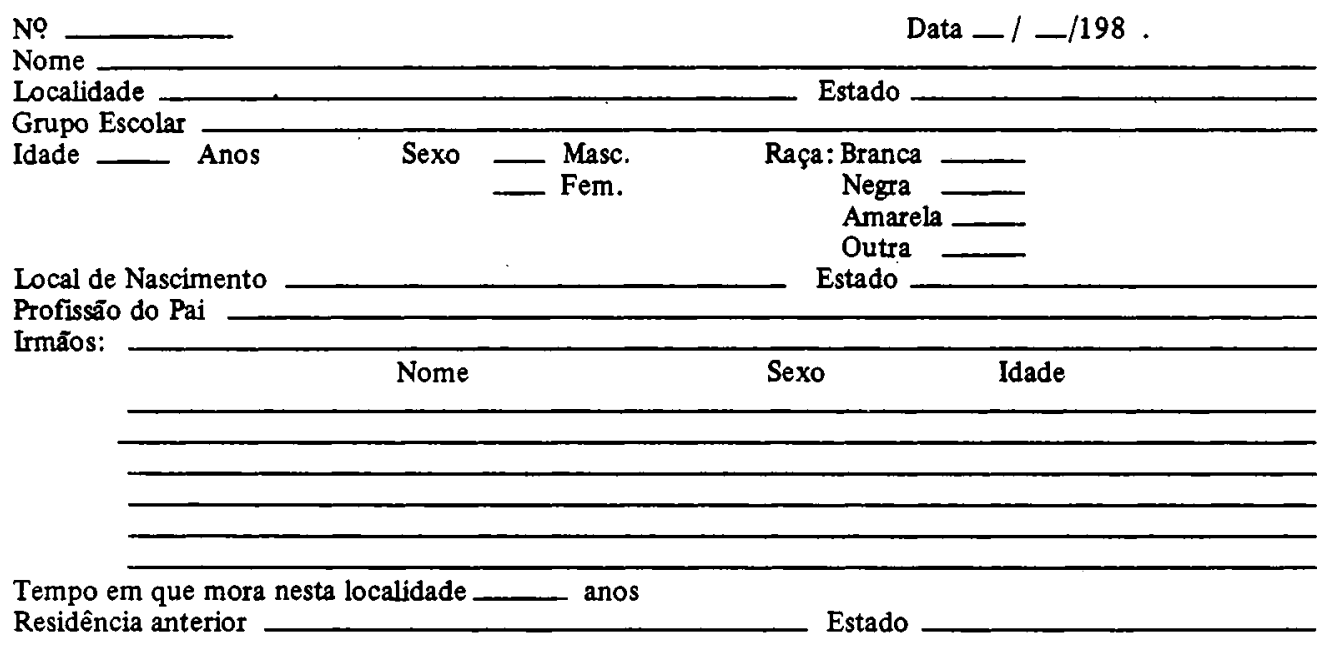

\section{Observaçōes:}

Nome do professor responsável

(Verso)

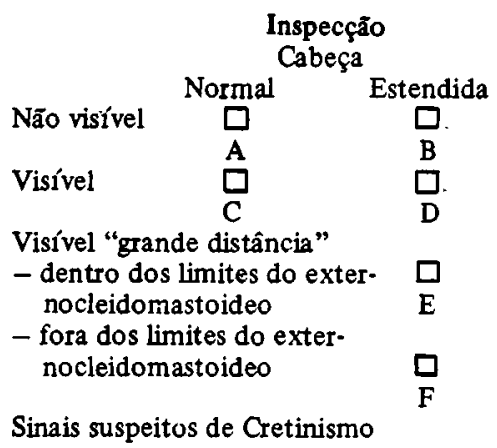

Observações:

Nome do Examinador:

\section{Palpação}

Não palpável ou palpável e de tamanho normal (unha do polegar)

Palpável tamanho entre o Normal e $0<$ que 4 - 5 x o Normal (falange distal do polegar)

Palpável $\geqslant$ que 4 - 5 x o tamanho Normal

Nódulos

$\underset{\operatorname{Sim}}{\square} \stackrel{\square}{\text { Não }}$ 